\title{
Protective Effects of Sumatriptan on Renal Ischemia-reperfusion Injury in Male Rats
}

\section{Mohammad Sheibani ${ }^{1}$, Yaser Azizi ${ }^{2,3}$, Maryam Shayan ${ }^{4,5}$, Sadaf Nezamoleslami $^{4,5}$, Faezeh Eslami ${ }^{4,5}$, Nafise Noroozi ${ }^{4,5}$, Hasan Yousefi-Manesh $^{4,5}$, Amin Ohadi ${ }^{4,5}$, Fereshteh Dalouchi ${ }^{3}$ and Ahmad Reza Dehpour ${ }^{4,5 *}$}

${ }^{1}$ Department of Pharmacology, School of Medicine, Iran University of Medical Sciences, Tehran, Iran

${ }^{2}$ Physiology Research Center, School of Medicine, Iran University of Medical Sciences, Tehran, Iran

${ }^{3}$ Department of Physiology, School of Medicine, Iran University of Medical Sciences, Tehran, Iran

${ }^{4}$ Department of Pharmacology, School of Medicine, Tehran University of Medical

Sciences, Tehran, Iran

${ }^{5}$ Experimental Medicine Research Center, Tehran University of Medical Sciences,

Tehran, Iran

*Corresponding Author: Ahmad Reza Dehpour, Professor, Department of Pharmacology,

School of Medicine, Tehran University of Medical Sciences, Tehran, Iran.
Received: November 03, 2021

Published: November 12, 2021

(C) All rights are reserved by Ahmad Reza

Dehpour., et al.

\begin{abstract}
Aim: The production of pro-inflammatory cytokines is one of the underlying reasons for renal ischemia/reperfusion injury (RIRI) that can cause functional disorders in the kidneys. Anti-inflammatory effects of sumatriptan had proved in previous studies. In this study, we aimed to evaluate the protective effect of sumatriptan on renal ischemia/reperfusion injury in rats.

Methods: Both renal arteries of animals in ischemia/reperfusion (I/R) groups clamped by clips for 45 minutes. In pretreatment groups with a single dose of sumatriptan, animals received $0.1,0.3,1$, and $3 \mathrm{mg} / \mathrm{kg}$ doses 30 minutes before I/R. Finally, after 24 hours, rrenal function markers-Blood Urea Nitrogen (BUN), Creatinine (Cr), and Lactate Dehydrogenase (LDH), serum level of inflammatory mediators (TNF- $\alpha$, IL-1 $\beta$, and NF-KB), tissue levels of oxidative factors (MDA and MPO), and histopathological changes were evaluated.

Results: Sumatriptan at the doses of $0.1,0.3$, and $1 \mathrm{mg} / \mathrm{kg}$ could significantly decrease the inflammatory factors like TNF- $\alpha$, IL-1 $\beta$, and NF-кB. The MDA and MPO tissue levels were respectively reduced considerably at $(0.3$ and $1 \mathrm{mg} / \mathrm{kg})$ and $(0.3,0.1, \mathrm{and} 1 \mathrm{mg} /$ $\mathrm{kg}$ ) doses. All treatment groups showed a significant decrease in serum BUN levels. Sumatriptan treatment also reduced Cr and LDH serum levels at $(0.3 \mathrm{mg} / \mathrm{kg})$ and $(0.3$ and $1 \mathrm{mg} / \mathrm{kg})$ doses, respectively. Treatment of rats with $0.3 \mathrm{mg} / \mathrm{kg}$ sumatriptan resulted in remarkable improvement in histopathological damage compared to the I/R group.

Conclusion: Our observation suggests that treatment with low doses of sumatriptan attenuates renal I/R injuries through its antiinflammatory and anti-oxidative properties.
\end{abstract}

Keywords: Sumatriptan; Renal Ischemia/Reperfusion; Inflammation; TNF- $\alpha$; IL-1 $\beta$; NF-kB; MDA; MPO; Cr; BUN 


\section{Introduction}

Renal ischemia/reperfusion injury (RIRI) is defined as an abrupt short-term interruption of blood flow, mostly a result of hemorrhagic shock, renal transplantation, and hydronephrosis. RIRI is one of the underlying causes of acute renal failure (ARF), carrying major costs for health care systems, and is also responsible for increasing the rate of morbidity and mortality. Ischemiainduced hypoxia, ATP depletion, and tubular epithelial cell injury eventually cause acute tubular necrosis (ATN). RIRI rat models can elucidate our understanding of subsequent molecular events and expand our knowledge of new drug treatments for RIRI [1-3].

Animal models of renal ischemia/reperfusion (I/R) injury demonstrated that secondary injury due to robust inflammatory reactions are as important as the initial RIRI. Studies have suggested many inflammatory pathways and components effective in RIRI. For example, Nuclear factor-kappa B (NF-кB) will increase immediately after injury activating cellular response and producing inflammatory proteins. Cellular responses include activation and immigration of T-cells, macrophages, and neutrophils, which produce inflammatory chemokines such as Interleukin $1 \beta$ (IL-1 $\beta$ ) and Tumor necrosis factor- $\alpha$ (TNF- $\alpha$ ). Early production of TNF- $\alpha$ upregulates adhesion molecules contributing to neutrophil infiltration evaluated by Myeloperoxidase (MPO) concentration. Kianian., et al. showed that the detected reduction in renal anti-oxidant capacity and enhanced production of oxidative markers like malondialdehyde (MDA) following renal I/ $R$ is due to systemic inflammation. Hence many drugs targeting inflammation may be utilized to ameliorate kidney injuries following I/R [2,4-7].

5-hydroxytryptamine (5-HT) or serotonin plays a vital role in renal metabolism and blood flow [8]. Serotonin is produced remarkably by proximal tubules, and its receptor becomes one of the most important therapeutic targets for many disorders such as hypertension [8]. Furthermore, investigations manifest that the stimulation of the 5-HT receptor will suppress TNF- $\alpha$ activation and inflammatory responses $[9,10]$. Sumatriptan is a 5 HT1B/1D receptor agonist, a preferred medication for migraine due to its vasoconstrictive effect. Still, recent studies proved that other mechanisms are involved in the anti-inflammatory effects of sumatriptan through serotonin receptors activation [11]. Anti-inflammatory effects of a low dose of sumatriptan have improved myocardial and testicular I/R injury in rat models $[9,12,13]$. However, we detected controversial results from the protective effects of sumatriptan in our previous study in the rat model of IRI injury. The mentioned study demonstrated a deteriorative impact of high doses of sumatriptan in renal I/R injury [14]. Furthermore, there is a lack of evidence about the anti-inflammatory and protective properties of low doses of sumatriptan on renal IRI. According to this description, we aimed to investigate the protective effects of low doses of sumatriptan in a rat model of renal IRI in this research.

\section{Materials and Methods}

Animals

Our study was in agreement with the Declaration of Helsinki. Furthermore, all experimental procedures were in accordance with the Guide for the Care and Use of Laboratory Animals (8th edition, National Academies Press). In addition, the Institutional Animal Ethical Committee of Tehran University of Medical Sciences has approved the study protocol. (Ethical approval number: IR.TUMS. VCR.REC.1397.074). Animals were purchased from the animal house of Tehran University of Medical Sciences. The animals were kept at optimal environments $\left(20 \pm 2{ }^{\circ} \mathrm{C}\right.$ and $12 \mathrm{~h}$ light-dark cycle), and food and water were available to them without restriction.

\section{Experimental design}

49 male Wistar rats weighing between $250-300$ g, randomly classified into seven groups: 1) Control (without any intervention), 2) Sham (animals with midline incision which received vehicle), 3) I/R (ischemia/reperfusion) untreated group (animals with surgical process and both renal arteries clamping which received vehicle), 4) I/R+ sumatriptan $0.1 \mathrm{mg} / \mathrm{kg}$, 5) I/R+ sumatriptan $0.3 \mathrm{mg} /$ $\mathrm{kg}, 6) \mathrm{I} / \mathrm{R}+$ sumatriptan $1 \mathrm{mg} / \mathrm{kg}, 7$ ) I/R+ sumatriptan $3 \mathrm{mg} / \mathrm{kg}$.

In the sham group, normal saline $(0.9 \% \mathrm{NaCl})$ as a vehicle was intraperitoneally injected. In the treatment groups, animals received different doses of sumatriptan (purchased from Sigma, St. Louis, MO, USA) intraperitoneally 30 minutes before I/R surgery.

\section{Inducing renal ischemia/reperfusion injury}

In order to induce the RIRI model in rats, we followed the same method in our previous study [1]. In this process, after anesthetizing the rats with ketamine $(75 \mathrm{mg} / \mathrm{kg})$ and xylazine $(10 \mathrm{mg} / \mathrm{kg})$ intraperitoneally, the abdominal wall and peritoneal cavity were opened with a small incision, and the renal artery blood flow was cut off gently with standard clips for 45 minutes at both sides. 
When the kidneys become pale (ischemic phase), it is safe to say that renal arteries are correctly occluded. After 45 minutes, the clamps were removed to start the reperfusion phase. Following that, the abdominal wall layers were sutured with a 3-0 nylon suture. Upon the blood return to the kidneys after the ischemic phase, the kidneys went through a reperfusion phase for 24 hours. In the four treatment groups, sumatriptan $(0.1,0.3,1$, and $3 \mathrm{mg} / \mathrm{kg})$ was administered through intraperitoneal (i.p.) injection 30 minutes before surgery.

\section{Collection of blood and kidney samples}

Twenty-four hours after blood flow restoration, so-called reperfusion, the animals were anesthetized again, and blood samples were collected from the heart's right ventricle. Then, to evaluate the inflammatory mediators, oxidative factors, and kidney function markers, the serum of the blood samples was separated after centrifugation, and the samples were then stored at $-80{ }^{\circ} \mathrm{C}$. The kidneys were also removed from the abdomen, and one of them was preserved at $-80{ }^{\circ} \mathrm{C}$ to evaluate the tissue oxidative stress markers. The other kidney was placed in $10 \%$ formalin for histopathological study.

\section{Assessment of kidney function markers}

We analyzed Blood Urea Nitrogen (BUN) and Creatinine (Cr) serum levels to assess renal function. Also, serum concentration of Lactate Dehydrogenase (LDH), the indicator of cellular injury, was measured from stored serum samples. This evaluation was performed at the Biochemistry Laboratory of Tehran University of Medical Sciences by an automatic analyzer.

\section{Measurement of serum levels of TNF- $\alpha$, IL-1 $\beta$, and NF-KB}

To evaluate the role of inflammation in the progression of RIRI, we measured the serum levels of tumor necrosis factor- $\alpha$ (TNF- $\alpha$ ), Interleukin $1 \beta$ (IL-1 $\beta$ ), and Nuclear factor-kappa B (NF-KB) through an enzyme-linked immunosorbent assay (ELISA) kit. This evaluation was performed following the specific instructions for each kit; TNF- $\alpha$ (RAB0479, Sigma Aldrich, United States), IL-1 $\beta$ (RAB0277, Sigma Aldrich, United States), and NF-кB (Cloud-Clone Corp., USA and R\&D Systems, USA; Catalog number: ABIN6958236). Finally, the absorbance of the samples was measured at $450 \mathrm{~nm}$ using an ELISA reader device (Bio-Tek Synergy HT, US). The levels of (TNF- $\alpha$ and IL-1 $\beta$ ) and NF-KB were reported as $\mathrm{pg} / \mathrm{ml}$ and $\mathrm{ng} / \mathrm{ml}$, respectively $[15,16]$.

\section{Evaluation of oxidative stress and lipid peroxidation}

We evaluated the tissue activity of the MPO enzyme and tissue levels of MDA to assess the extent of lipid peroxidation and oxidative stress activity in kidney tissues previously-stored at $-80^{\circ} \mathrm{C}$. The enzyme-linked immunosorbent assay (ELISA) kit (Sigma Aldrich, United States) was utilized to measure tissue MPO enzyme activity. This process was performed according to the manufacturer's instructions. First, the MPO levels were presented as Unit/gr kidney tissue. Then, to evaluate the kidney levels of MDA, renal tissue was homogenized with $50 \mathrm{mM}$ Tris- HCL buffer solution with $\mathrm{pH}=7.4$. After tissue homogenization and centrifugation (at 10,000 $\mathrm{g}$ and $4^{\circ} \mathrm{C}$ for $30 \mathrm{~min}$ ), the obtained solution was called tissue solution. After this, another combination consisting of $0.75 \mathrm{ml}$ of acetic acid, $0.1 \mathrm{ml}$ of sodium dodecyl sulfate, $0.3 \mathrm{ml}$ of distilled water, 0.75 $\mathrm{ml}$ of thiobarbituric acid, and $0.1 \mathrm{ml}$ prepared tissue solution were poured into the tubes. Then, after heating $\left(95^{\circ} \mathrm{C}\right.$ for one hour) and cooling with ice water, they were vortexed after adding distilled water and n-butanol/pyridine. Finally, after centrifugation of the tubes at $3000 \mathrm{rpm}$ for $10 \mathrm{~min}$, the supernatant absorbance was measured at $532 \mathrm{~nm}$, and the results were reported as nmol/mg of protein. This technique was performed according to the protocol that was previously defined [17].

\section{Histopathological assessment}

One of the kidneys fixed in 10\% formalin solution was used for kidney histopathological study. First, the tissues were embedded with paraffin and cut into four $\mu \mathrm{m}$ slices. In the next step, prepared slides were stained with hematoxylin and eosin (H\&E). After that, they were studied using a standard optical microscope with magnification $\times 400$. Finally, a blinded pathologist assessed the comparison between the groups regarding the degree of renal tubular necrosis, intercellular edema, hemorrhage, and epithelial cell damage [18-20].

\section{Statistical analysis}

To analyze the data, we used Graph Pad Prism software, version 5; comparisons between groups were performed through one-way ANOVA followed by Tukey's post hoc test. Results were presented as mean \pm SEM. A probability value (P-value) less than 0.05 was considered statistically significant.

\section{Results}

In all evaluated factors, there was no statistical difference between the control group and the sham group. Therefore, based on 
the results achieved from this study, sumatriptan at the dose of 0.3 $\mathrm{mg} / \mathrm{kg}$ showed better protective and therapeutic effects than other treatment groups. As a result, we compared only $0.3 \mathrm{mg} / \mathrm{kg}$ sumatriptan treated group with other sumatriptan received groups to demonstrate the most effective dose of sumatriptan in this model.

\section{Effects of sumatriptan on renal function markers}

BUN and Cr were evaluated as markers of renal function. As table 1 shows, serum levels of BUN and $\mathrm{Cr}$ in the I/R group increased significantly compared to the control group ( $\mathrm{P}<0.001)$. Thus, Sumatriptan could remarkably decrease the serum levels of BUN in all treatment groups compared with the I/R group. Also, all treatment groups with sumatriptan had a statistical difference com- pared to the control group $(\mathrm{P}<0.001)$. Statistical analysis between the treatment groups showed that sumatriptan at the dose of 0.3 $\mathrm{mg} / \mathrm{kg}$ could significantly reduce the serum level of BUN compared to the other treatment groups (sumatriptan $0.1 \mathrm{mg} / \mathrm{kg}(\mathrm{P}<0.001)$, sumatriptan $1 \mathrm{mg} / \mathrm{kg}(\mathrm{P}<0.05)$, and sumatriptan $3 \mathrm{mg} / \mathrm{kg}(\mathrm{P}<$ 0.001). However, the serum $\mathrm{Cr}$ level reduction was significant only in the $0.3 \mathrm{mg} / \mathrm{kg}$ sumatriptan treated group compared to the I/R group ( $\mathrm{P}<0.01)$. Moreover, 0.1 and $3 \mathrm{mg} / \mathrm{kg}$ sumatriptan treated groups had higher serum $\mathrm{Cr}$ levels than the control group $(\mathrm{P}<0.05$ and $\mathrm{P}<0.01$, respectively). Besides, in the analysis of serum $\mathrm{Cr}$ level, sumatriptan at a dose of $3 \mathrm{mg} / \mathrm{kg}$ showed a more significant therapeutic difference compared to the $0.3 \mathrm{mg} / \mathrm{kg}$ sumatriptan treated rats $(\mathrm{P}<0.05)$.

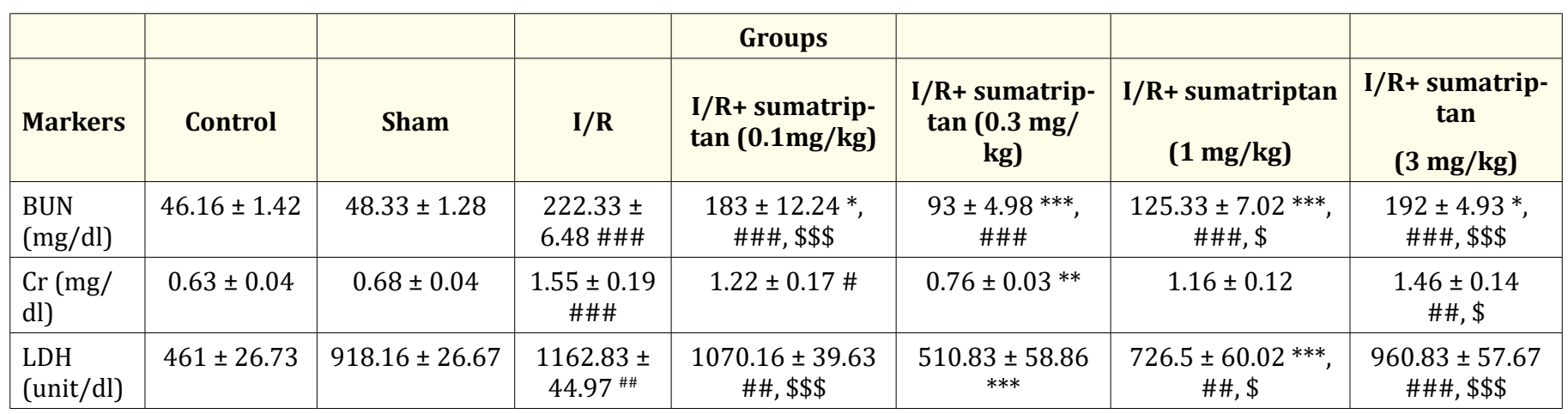

Table 1: Serum levels of BUN, Cr and LDH in different groups. Data are presented as mean \pm SEM. \#\#\#P < 0.001; compared to the sham group. ${ }^{*} \mathrm{P}<0.05,{ }^{* *} \mathrm{P}<0.01$, and ${ }^{* * *} \mathrm{P}<0.001$; compared to the I/R group. $\$ \mathrm{P}<0.05$ and $\$ \$ \$ \mathrm{P}<0.001$ compared to the I/R+ sumatriptan $(0.3 \mathrm{mg} / \mathrm{kg})$ group $(\mathrm{n}=7)$.

I/R: Ischemia/Reperfusion, Cr: Creatinine, BUN: Blood Urea Nitrogen, LDH: Lactate Dehydrogenase.

Also, the serum LDH level of the I/R group was higher significantly than the control group $(\mathrm{P}<0.01)$. Therefore, administering sumatriptan at the doses of 0.3 and $1 \mathrm{mg} / \mathrm{kg}$ could decrease the serum level of LDH compared to the I/R group $(\mathrm{P}<0.001)$. Moreover, treatment with sumatriptan at the doses of $0.1,1$, and $3 \mathrm{mg} /$ $\mathrm{kg}$ showed statistical difference compared to the control group ( $\mathrm{P}$ $<0.001, \mathrm{P}<0.01$, and $\mathrm{P}<0.001$, respectively) and LDH level in the sumatriptan $(0.3 \mathrm{mg} / \mathrm{kg})$ treatment group was very close to the control group. Furthermore, evaluation of treatment groups demonstrated that serum level of the LDH in the $0.3 \mathrm{mg} / \mathrm{kg}$ sumatriptan treated group was significantly lower than other sumatriptan $(0.1$, 1 , and $3 \mathrm{mg} / \mathrm{kg})$ treated groups $(\mathrm{P}<0.001, \mathrm{P}<0.05$, and $\mathrm{P}<0.001$, respectively).
Effects of sumatriptan on serum levels of inflammatory factors

Figure 1 represents that serum levels of all inflammatory factors including IL-1 $\beta$, TNF- $\alpha$, and NF-KB in the I/R group were dramatically higher than the control group $(\mathrm{P}<0.001)$. Based on figure $1 \mathrm{~A}$, serum concentration of IL- $1 \beta$ in the sumatriptan $(0.1,0.3$, and $1 \mathrm{mg} / \mathrm{kg}$ ) treated groups was decreased significantly as compared with the I/R group $(\mathrm{P}<0.01, \mathrm{P}<0.001$, and $\mathrm{P}<0.001$, respectively). Moreover, all treatment groups with sumatriptan showed a remarkable reduction compared to the control group $(\mathrm{P}<0.001)$. Administration of $0.3 \mathrm{mg} / \mathrm{kg}$ sumatriptan could effectively reduce the serum level of IL- $1 \beta$ compared to the other treatment groups $(0.1$ $\mathrm{mg} / \mathrm{kg}(\mathrm{P}<0.001), 1 \mathrm{mg} / \mathrm{kg}(\mathrm{P}<0.01)$, and $3 \mathrm{mg} / \mathrm{kg}(\mathrm{P}<0.001)$. 


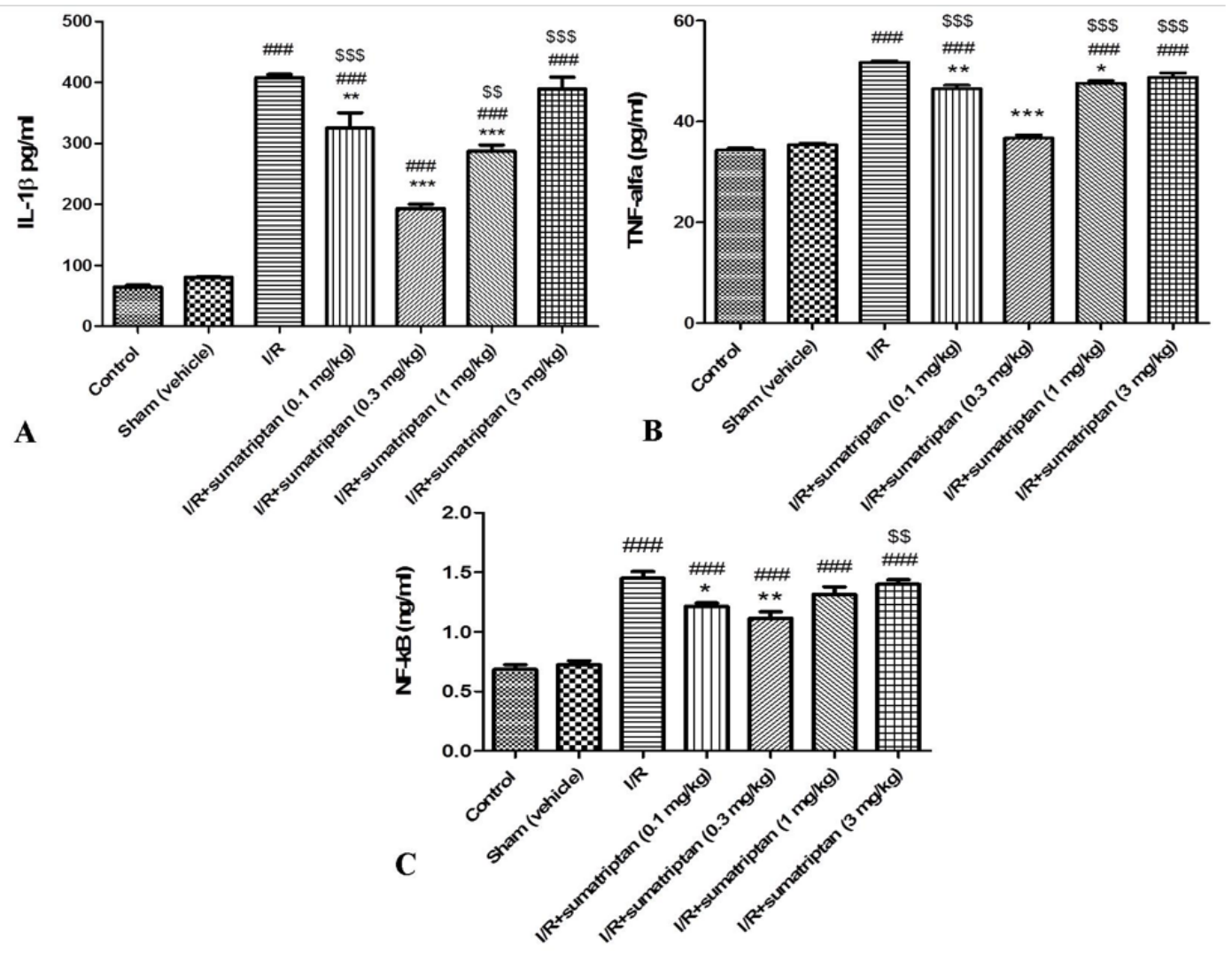

Figure 1: Effect of sumatriptan on the serum levels of IL-1 $\beta(A)$, TNF- $\alpha(B)$, and NF- $\kappa B(C)$ in different groups $(n=7)$. Data are presented as mean \pm SEM. \#\#\#P $<0.001$; compared to the control group. ${ }^{*} \mathrm{P}<0.05$, ${ }^{* *} \mathrm{P}<0.01$, and ${ }^{* * *} \mathrm{P}<0.001$; compared to the $\mathrm{I} / \mathrm{R}$ group. $\$ \$ \mathrm{P}<$ 0.01 and $\$ \$$ P $<0.001$ compared to the $\mathrm{I} / \mathrm{R}+$ sumatriptan $(0.3 \mathrm{mg} / \mathrm{kg})$ group. I/R: Ischemia/reperfusion.

Statistical analysis showed a remarkable diminish in serum TNF- $\alpha$ level in the sumatriptan treated groups at the doses of 0.1 $\mathrm{mg} / \mathrm{kg}(\mathrm{P}<0.01), 0.3 \mathrm{mg} / \mathrm{kg}(\mathrm{P}<0.001)$, and $1 \mathrm{mg} / \mathrm{kg}(\mathrm{P}<0.05)$ in comparison with the I/R group. There was no statistical significance between the $3 \mathrm{mg} / \mathrm{kg}$ sumatriptan treatment and I/R groups (Figure 1B). Except for the $0.3 \mathrm{mg} / \mathrm{kg}$, sumatriptan treated group, all treatment groups showed higher serum levels of TNF- $\alpha$ than the control group $(\mathrm{P}<0.001)$. The serum level of TNF- $\alpha$ in the sumatriptan $(0.3 \mathrm{mg} / \mathrm{kg})$ treatment group was very close to the control group. Treatment with sumatriptan at the dose of $0.3 \mathrm{mg} / \mathrm{kg}$ could suppress the serum TNF- $\alpha$ level more effectively than other sumatriptan treatment doses $(\mathrm{P}<0.001)$. As a result, the highest reduction in serum TNF- $\alpha$ level was observed after the $0.3 \mathrm{mg} / \mathrm{kg}$ sumatriptan treatment.
As expected, serum NF- $\mathrm{KB}$ concentration, which is considered as a marker to show the activity of inflammatory pathways, increased in the I/R group compared to the control group $(\mathrm{P}<0.001)$ and decreased significantly in the $0.3 \mathrm{mg} / \mathrm{kg}(\mathrm{P}<0.01)$ and $0.1 \mathrm{mg} / \mathrm{kg}(\mathrm{P}<$ 0.05 ) sumatriptan treated groups compared to the I/R group (Figure $1 \mathrm{C}$ ). Also, there was statistical significance between all sumatriptan treated groups and the control group $(\mathrm{P}<0.001)$. Comparison between the treatment groups demonstrated that the serum level of NF-KB only in the $3 \mathrm{mg} / \mathrm{kg}$ treated group was remarkably higher than the $0.3 \mathrm{mg} / \mathrm{kg}$ sumatriptan treated group $(\mathrm{P}<0.01)$.

\section{Effects of sumatriptan on oxidative stress factors}

As shown in figure 2A, in the I/R group, the kidney tissue levels of MPO was significantly elevated compared to the control group (P 
$<0.001)$. Statistical analysis showed a significant reduction in MPO level in $0.1,0.3$, and $1 \mathrm{mg} / \mathrm{kg}$ sumatriptan treated groups as compared with the I/R group $(\mathrm{P}<0.01, \mathrm{P}<0.001$, and $\mathrm{P}<0.05$, respectively). Moreover, a significant increase was observed in all treatment groups with sumatriptan compared to the control group $(\mathrm{P}<$ 0.001). Also, there was a statistically significant difference between the tissue levels of MPO in the $0.3 \mathrm{mg} / \mathrm{kg}$ sumatriptan treated and the other three treatment groups $(\mathrm{P}<0.001)$.

Compared to the control group, MDA in the I/R group increased significantly following I/R $(\mathrm{P}<0.001)$. On the other hand, the tissue MDA level was dramatically decreased following administration of
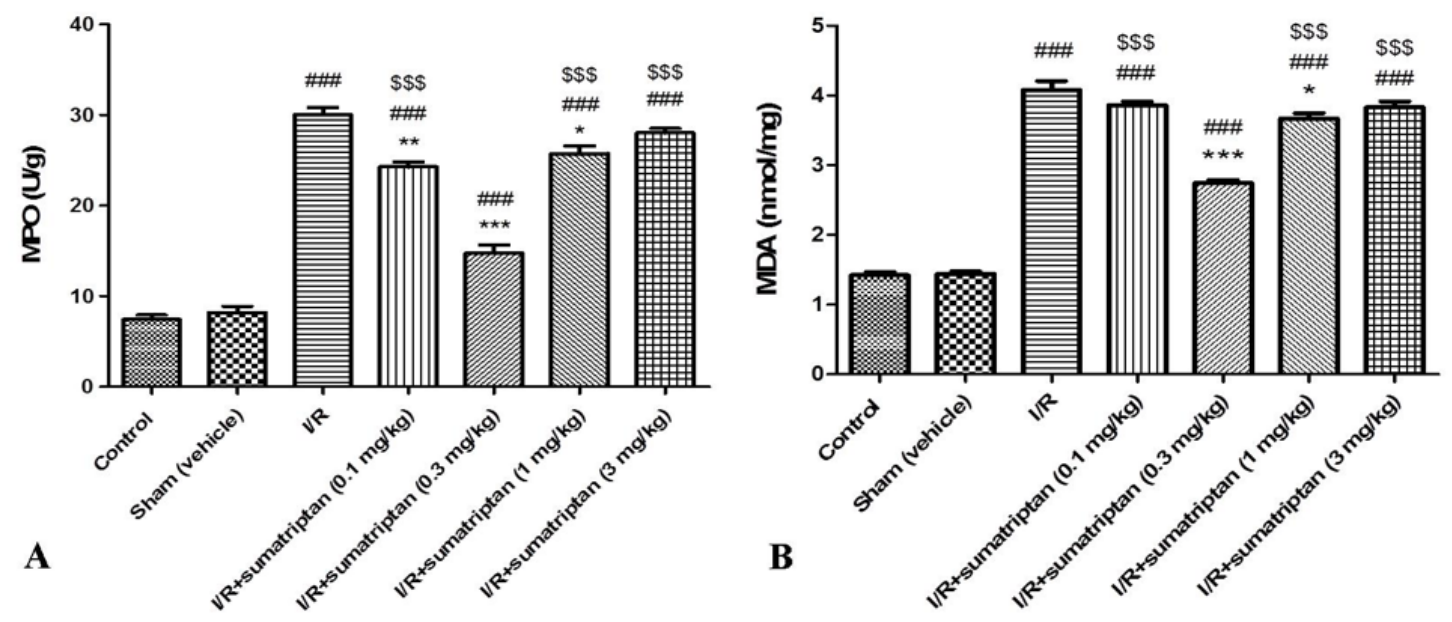

Figure 2: Effect of sumatriptan on kidney tissue levels of MPO (A) and MDA (B) in different groups ( $\mathrm{n}=7)$. Data are presented as mean \pm SEM. \#\#\#P $<0.001$; compared to the control group. ${ }^{*} \mathrm{P}<0.05$, ${ }^{* *} \mathrm{P}<0.01$, and ${ }^{* * *} \mathrm{P}<0.001$; compared to the I/R group. $\$ \$ \mathrm{P}<0.001$ compared to the I/R+ sumatriptan $(0.3 \mathrm{mg} / \mathrm{kg})$ group. I/R: Ischemia/reperfusion.

0.3 and $1 \mathrm{mg} / \mathrm{kg}$ sumatriptan $(\mathrm{P}<0.001$ and $\mathrm{P}<0.05$, respectively) compared with the I/R group (Figure 2B). However, all sumatriptan-treated groups showed statistical differences from the control group ( $\mathrm{P}<0.001)$. Also, there was a statistical difference between the tissue levels of MDA in the $0.3 \mathrm{mg} / \mathrm{kg}$ sumatriptan treated group and the other three treatment groups $(\mathrm{P}<0.001)$.

\section{Kidney histopathological changes}

Figure 3 illustrates histopathological changes in the kidney tissues stained with (H\&E) in all experimental groups. Normal histology of the kidney tissue and normal structures of glomeruli and renal tubules were shown in normal and sham undergone animals (Figure 3A and 3B). Induction of ischemia for 45 min caused sev- eral degenerative histological changes such as tubular dilation, wider renal spaces, especially in renal corpuscles, degeneration of the glomeruli with necrosis, and vacuolar degeneration of tubular cells (Figure 3C). In the kidney tissues treated with sumatriptan $0.3 \mathrm{mg} / \mathrm{kg}$ (Figure 3E), photomicrographs showed almost normal structure with normal tubules and glomeruli similar to the control group. However, in the kidney tissues treated with higher doses of sumatriptan, there was less improvement of pathological changes induced by I/R (Figure $3 \mathrm{~F}$ and $3 \mathrm{G}$ ).

\section{Discussion}

Ischemia/reperfusion injury (IRI) is a great concern follow- 

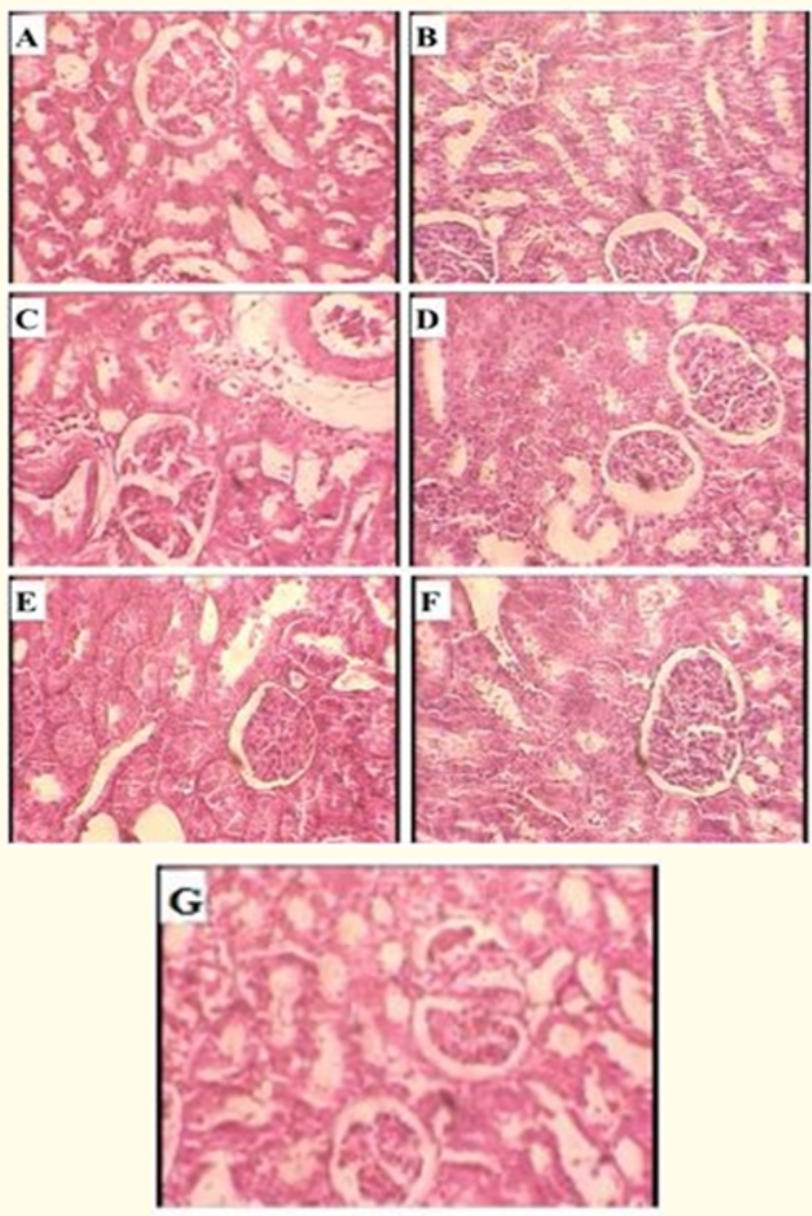

Figure 3: Effect sumatriptan on pathological changes of kidney tissue in different groups $(n=7)$. Data are presented as mean \pm SEM. Normal (A), Sham (vehicle) (B), Control (I/R) (C), I/R+sumatriptan $(0.1 \mathrm{mg} / \mathrm{kg})(\mathrm{D}), \mathrm{I} / \mathrm{R}+$ sumatriptan $(0.3 \mathrm{mg} / \mathrm{kg})(\mathrm{E}), \mathrm{I} / \mathrm{R}+$ sumatrip$\tan (1 \mathrm{mg} / \mathrm{kg})(\mathrm{F})$, and I/R+sumatriptan $(3 \mathrm{mg} / \mathrm{kg})(\mathrm{G})$.

ing renal transplant due to hypoxia and subsequent inflammation, which causes acute and chronic graft rejection [21]. Hence many researchers are looking for therapeutic methods to prevent AKI post-IRI. In the present study, protective effects of low doses of sumatriptan were observed in a rat model of IRIR. Biochemically, a significant reduction of inflammatory cytokines including NF- $\kappa B$, IL-1 $\beta$, TNF- $\alpha$, and diminished tissue MPO, MDA, and LDH levels was seen in our experiment while using low doses of sumatriptan as a pretreatment for RIRI in the rat model. In addition, renal function markers (BUN and $\mathrm{Cr}$ ) were also improved following sumat- riptan administration. Moreover, histopathological damage was remarkably attenuated in the $0.3 \mathrm{mg} / \mathrm{kg}$ sumatriptan treated group compared to the I/R group.

Xu., et al. showed that serum $\mathrm{Cr}$ and BUN levels increased after IRI, and they suggested that inflammatory responses play a significant role in this elevation [22]. In many studies, BUN and $\mathrm{Cr}$ are considered as renal function markers for the development of renal injury in kidney disorders [1]. In agreement with previous reports, our study demonstrated that the serum level of BUN and Cr were elevated significantly after 24 hours of ischemia/reperfusion in the I/R group compared with the control group. This elevation may be due to the electrolyte homeostasis impairment and decreased glomerular filtration rate (GFR) [23]. The data achieved from our study demonstrated that lower doses of sumatriptan (0.3 and 0.1 $\mathrm{mg} / \mathrm{kg}$ ) remarkably decrease both of these biomarkers. In addition, lactate dehydrogenase (LDH) rises in many inflammatory states and is measured to quantify necrosis and ischemia deterioration.

For this reason, it is an essential indicator of cellular injury and tissue necrosis in many inflammatory models, especially in renal disorders [1]. The key role of LDH in stimulating inflammation and the correlation between LDH and exacerbation of inflammation were also highlighted in some papers. For example, LDH can induce pro-inflammatory cytokines production. In our study, sumatriptan at lower doses ( 0.1 and $0.3 \mathrm{mg} / \mathrm{kg}$ ) significantly reduced the serum level of LDH compared to the I/R group [24,25].

Besides, direct cytotoxic effects of inflammation after reperfusion can lead to massive destruction of parenchymal cells of the kidney that called acute tubular necrosis (ATN); thus, drugs with anti-inflammatory properties may suppress the IRI. The inflammatory process may initiate following the release of inflammatory factors from necrotic cells or depleting anti-inflammatory cytokines. As a result, measuring inflammatory markers is a valuable target for determining drug efficacy [2]. One factor that exacerbates renal I/R damage is leukocytes activated by reactive oxygen species (ROS) and pro-inflammatory cytokines such as IL-1 $\beta$ and TNF- $\alpha$. The renal tubular epithelium also produces these cytokines. Also, Increasing these cytokines and oxidative stress activation can induce IRI [26]. A study by Liu., et al. showed that the pre inflammatory cytokines and ROS increase in renal IRI. Their result demonstrated that treatment with Trehalose could improve the RIRI by 
enhancing autophagy and blocking oxidative stress, inflammation, and apoptosis [27]. The opioid pathway also plays a crucial role in suppressing inflammatory markers and protecting renal ischemia/ reperfusion. Opioid preconditioning and morphine dependence protect against ischemia/reperfusion injuries in the kidney and heart. By adjusting the dose of opioid agonists, the harms can be avoided while the benefits can be used [28-30].

Hypoxia and subsequent necrosis in renal IRI lead to the upregulation of NF-KB expression in tubular epithelial cells (TEC) as a first inflammatory response. NF-KB is a crucial factor for the secretion of the downstream cytokines [2]. Moreover, it was previously accepted that the overproduction of NF-KB occurs during renal IRI [31]. In the present study, the serum level of NF-KB increased $24 \mathrm{~h}$ after renal injury, and pretreatment with 0.1 and $0.3 \mathrm{mg} / \mathrm{kg}$ sumatriptan caused a significant reduction in serum NF-KB concentration. Maybe it can be concluded that the lower doses of sumatriptan could diminish the serum level of IL- $1 \beta$ and TNF- $\alpha$, maybe through reduction of NF-KB. One of the critical inflammatory cytokinesis is TNF- $\alpha$. This pro-inflammatory cytokine can upregulate the expression of other inflammatory factors. Renal parenchymal cells and local renal macrophages produce TNF- $\alpha$ at the onset of the IRI [1,2]. TNF- $\alpha$ also upregulates the expression of adhesion molecules such as ICAMs and VCAMs via autocrine and paracrine effects, resulting in infiltration of neutrophils and other leukocytes in kidney tissue [5]. In agreement with previous research, [32] in this work, the increased serum level of TNF-a and IL-1 $\beta$ has observed Sumatriptan at lower doses, resulting in a remarkable reduction in serum levels of these inflammatory cytokines. Dehpour., et al. reported similar effects of sumatriptan on TNF- $\alpha$ and IL-1 $\beta$ in some inflammatory models such as cardiac IRI and status epilepticus in rats. Ischemia/ reperfusion leads to systemic damage by inducing inflammation and activation of oxidative stress pathways. Overproduction of lipid peroxidation, oxidative stress reactions, and ROS have a crucial role in IRI $[9,11,12]$.

On the other hand, these factors provoke cellular damage and promote myeloperoxidase (MPO) production, generating inflammatory responses [33,34]. In addition, neutrophil Infiltration, which was found in tubular biopsy of ATN, proved that neutrophils play a critical role in the renal IRI. The above studies used the MPO as a highly sensitive marker to determine neutrophil infiltration $[6,35]$. In many renal diseases, the MPO enzyme and its products are valuable indicators to estimate the development of different renal injuries $[35,36]$. The tissue levels of MPO significantly increased after renal IRI. But the results obtained from this study showed that lower doses of sumatriptan could decrease these elevated levels of MPO. Malondialdehyde (MDA) is a common marker of oxidative stress and is a final lipid peroxidation product. Many studies confirmed that MDA had been related to the development of renal IRI [37]. In confirmation of previous studies, we showed that the tissue MDA level elevated subsequent I/R injury. Following sumatriptan administration, especially at the dose of $0.3 \mathrm{mg} / \mathrm{kg}$, the renal level of MDA was significantly decreased in the I/R rats. This protective effect of sumatriptan has already been proven in an animal model [38]. As a result, sumatriptan can also preserve the balance between the oxidant and anti-oxidant factors by preventing MDA and MPO production and inhibiting ROS destructive effects.

We evaluated the renal histopathological damage for cellular and tubular injury assessment. Neutrophil infiltration is one of the leading causes of tissue damage in inflammatory conditions such as I/R [39]. In the sumatriptan treated group, particularly at the dose of $0.3 \mathrm{mg} / \mathrm{kg}$, the rate of neutrophil infiltration, tubulointerstitial damage, tissue edema, and cellular disarrangement in renal tissue improved compared to the I/R group. Thus, Sumatriptan could reduce the tissue damage caused by reperfusion by reducing neutrophilic infiltration. These results presented the protective effect of sumatriptan on renal histopathological changes during I/R.

One of the previous studies sumatriptan at the high doses had deteriorative effects in IRI [14]. But, in the present study, in confirmation with many of our research, sumatriptan at the low doses (dose-dependent manner) had anti-inflammatory and anti-oxidant properties. It can exert therapeutic effects on many inflammatory models [9-12,40,41]. Thus, the dose-dependent effects of sumatriptan justify this controversial effect. Furthermore, more analyses are needed to clarify the exact protective mechanisms of sumatriptan.

\section{Conclusion}

In conclusion, we found the protective effects of lower doses of sumatriptan in a rat model of renal IRI. These effects may be mediated by inhibiting the production of inflammatory mediators and suppressing oxidative stress activation. Improvement in the renal 
function markers and renal histopathological damage confirmed these findings. However, this study highlights the notion that sumatriptan is a compound with a narrow therapeutic index, and more research is required to explain the underlying therapeutic mechanisms of sumatriptan.

\section{Funding}

This study was supported by a grant from the Tehran University of Medical Sciences (TUMS) and Iran National Sciences Foundation (INSF).

\section{Disclosure of Interest}

The authors declare no conflict of interest.

\section{Ethics Approval}

All animal experiments were performed in agreement with the Guidelines for the Care and Use of Laboratory Animal Ethics Committee of Tehran University of Medical Sciences (Ethical code: IR.TUMS.VCR.REC.1397.074).

\section{Bibliography}

1. Nezamoleslami S., et al. "Protective effect of dapsone against renal ischemia-reperfusion injury in rat". Immunopharmacology and Immunotoxicology 42 (2020): 1-8.

2. Thurman JM. “Triggers of inflammation after renal ischemia/ reperfusion". Clinical Immunology 123.1 (2007): 7-13.

3. Williams P., et al. "Characterization of renal ischemia-reperfusion injury in rats". Journal of Pharmacological and Toxicological Methods 37.1 (1997): 1-7.

4. Sung FL., et al. "Enhanced MCP-1 expression during ischemia/ reperfusion injury is mediated by oxidative stress and NF-KB". Kidney International 62.4 (2002): 1160-1170.

5. Takada M., et al. "The cytokine-adhesion molecule cascade in ischemia/reperfusion injury of the rat kidney. Inhibition by a soluble P-selectin ligand". Journal of Clinical Investigation 99.11 (1997): 2682-2690.

6. Donnahoo KK., et al. "Early kidney TNF-alpha expression mediates neutrophil infiltration and injury after renal ischemiareperfusion". American Journal of Physiology 277.3 (1999): R922-929.

7. Kianian F., et al. "Protective effects of celecoxib on ischemia reperfusion-induced acute kidney injury: comparing between male and female rats". Iranian Journal of Basic Medical Sciences 22.1 (2019): 43.

8. Sole MJ., et al. "An active pathway for serotonin synthesis by renal proximal tubules". Kidney International 29.3 (1986): 689-694.

9. Eslami F., et al. "Sumatriptan Reduces Severity of Status Epilepticus Induced by Lithium-Pilocarpine Through Nitrergic Transmission and 5-HT 1B/D Receptors in Rats: A Pharmacological-Based Evidence". Fundamental and Clinical Pharmacology 35.1(2020): 131-140.

10. Dehpour AR., et al. "Evaluation of Anti-inflammatory and Antioxidant Effects of Sumatriptan on Carbon Tetrachloride-induced Hepatotoxicity in Rats". Drug Research (2021).

11. Afshari K., et al. "Sumatriptan improves the locomotor activity and neuropathic pain by modulating neuroinflammation in rat model of spinal cord injury". Neurological Research 43.1 (2021): 29-39.

12. Sheibani M., et al. "Sumatriptan protects against myocardial ischaemia-reperfusion injury by inhibition of inflammation in rat model". Inflammopharmacology 27.5 (2019): 1071-1080.

13. Dejban P., et al. "Protective effects of sumatriptan on ischaemia/reperfusion injury following torsion/detorsion in ipsilateral and contralateral testes of rat". Andrologia 51.9 (2019): e13358.

14. Mobasheran P., et al. "The effects of acute Sumatriptan treatment on renal ischemia/reperfusion injury in rat and the possible involvement of nitric oxide". Canadian Journal of Physiology and Pharmacology 98.4 (2019): 252-258.

15. Aryannejad A., et al. "Protective effect of modafinil on skin flap survival in the experimental random-pattern skin flap model in rats: The role of ATP-sensitive potassium channels and nitric oxide pathway". Journal of Plastic, Reconstructive and Aesthetic Surgery 74.6 (2021): 1346-1354.

16. Tabary M., et al. "Ivermectin Increases Random-Pattern Skin Flap Survival in Rats: The Novel Role of GABAergic System". Journal of Surgical Research 259 (2021): 431-441.

17. Ohkawa H., et al. "Assay for lipid peroxides in animal tissues by thiobarbituric acid reaction". Analytical Biochemistry 95.2 (1979): 351-358.

18. Shokrian Zeini M., et al. "Losartan ointment attenuates imiquimod-induced psoriasis-like inflammation". International Immunopharmacology 100 (2021): 108160. 
19. Amanlou A., et al. "Anticonvulsive evaluation and histopathological survey of thalidomide synthetic analogs on lithiumpilocarpine-induced status epilepticus in rats". Research in Pharmaceutical Sciences 16.6 (2021): 586-595.

20. Aryannejad A., et al. "Anti-inflammatory Effects of Ivermectin in the Treatment of Acetic Acid Induced Colitis in Rats: Involvement of GABAB Receptors". Digestive Diseases and Sciences (2021).

21. Salvadori M., et al. "Update on ischemia-reperfusion injury in kidney transplantation: Pathogenesis and treatment". World Journal of Transplantation 5.2 (2015): 52-67.

22. Xu Z., et al. "Dexmedetomidine attenuates renal and myocardial ischemia/reperfusion injury in a dose-dependent manner by inhibiting inflammatory response". Annals of Clinical and Laboratory Science 49.1 (2019): 31-35.

23. Bonventre JV and Yang L. "Cellular pathophysiology of ischemic acute kidney injury". The Journal of Clinical Investigation 121.11 (2011): 4210-4221.

24. Pucino V., et al. "Lactate at the crossroads of metabolism, inflammation, and autoimmunity". European Journal of Immunology 47.1(2017): 14-21.

25. Friedewald JJ and Rabb H. "Inflammatory cells in ischemic acute renal failure". Kidney International 66.2 (2004): 486491.

26. Bonventre JV and Zuk A. "Ischemic acute renal failure: an inflammatory disease?". Kidney International 66.2 (2004): 480485.

27. Liu S., et al. "Trehalose attenuates renal ischemia-reperfusion injury by enhancing autophagy and inhibiting oxidative stress and inflammation". American Journal of Physiology-Renal Physiology 318.4 (2020): F994-F1005.

28. Franco-Acevedo A., et al. "Opioid Preconditioning Modulates Repair Responses to Prevent Renal Ischemia-Reperfusion Injury". Pharmaceuticals 13.11 (2020): 387.

29. Habibey R and Pazoki-Toroudi H. "Morphine dependence protects rat kidney against ischaemia-reperfusion injury". Clinical and Experimental Pharmacology and Physiology 35.10 (2008): 1209-1214.

30. Zamanian G., et al. "Interaction of morphine tolerance with pentylenetetrazole-induced seizure threshold in mice: The role of NMDA-receptor/NO pathway". Epilepsy and Behavior 112 (2020): 107343.
31. DONNAHOO KK., et al. "Early renal ischemia, with or without reperfusion, activates NFKB and increases TNF- $\alpha$ bioactivity in the kidney". The Journal of Urology 163 .4 (2000): 1328-1332.

32. Xin Y., et al. "AS-IV protects against kidney IRI through inhibition of NF- $\mathrm{\kappa B}$ activity and PUMA upregulation". International journal of clinical and Experimental Medicine 8.10 (2015): 18293.

33. Jaeschke H and Woolbright BL. "Current strategies to minimize hepatic ischemia-reperfusion injury by targeting reactive oxygen species". Transplantation Reviews 26.2 (2012): 103-114.

34. Lashgari N-A., et al. "Current overview of opioids in progression of inflammatory bowel disease pharmacological and clinical considerations". Molecular Biology Reports 48.1 (2021): 855-874.

35. Burne-Taney MJ., et al. "Acute renal failure after whole body ischemia is characterized by inflammation and T cell-mediated injury". The American Journal of Physiology-Renal Physiology 285.1 (2003): F87-94.

36. Malle E., et al. "Myeloperoxidase in kidney disease". Kidney international 64.6(2003): 1956-1967.

37. Gaweł S., et al. "Malondialdehyde (MDA) as a lipid peroxidation marker". Wiadomosci lekarskie (Warsaw, Poland: 1960) 57.9-10 (2004): 453-455.

38. Gharishvandi F., et al. "Involvement of 5-HT1B/1D receptors in the inflammatory response and oxidative stress in intestinal ischemia/reperfusion in rats". European Journal of Pharmacology 882 (2020): 173265.

39. Hernandez LA., et al. "Role of neutrophils in ischemia-reperfusion-induced microvascular injury". American Journal of Physiology-Heart and Circulatory Physiology 253.3 (1987): H699-H703.

40. Khalilzadeh M., et al. "The protective effects of sumatriptan on vincristine-induced peripheral neuropathy in a rat model". Neurotoxicology 67 (2018): 279-286.

41. Sheibani M., et al. "Anti-Inflammatory and Antioxidative Effects of Sumatriptan Against Doxorubicin-Induced Cardiotoxicity in Rat". Acta Medica Iranica 59.7 (2021).

\section{Volume 5 Issue 12 December 2021}

(C) All rights are reserved by Ahmad Reza Dehpour., et al. 